\title{
Gastrointestinal morbidity and growth after repair of oesophageal atresia and tracheo-oesophageal fistula
}

\author{
P Chetcuti, P D Phelan
}

\begin{abstract}
Upper gastrointestinal morbidity and anthropometric data in 334 patients aged 1 to 37 years with repaired oesophageal atresia and tracheo-oesophageal fistula are reported. Two thirds were subsequently hospitalised with oesophageal complications and half underwent one or more surgical procedures. Thirteen percent were hospitalised for more than 50 days. Anastomotic strictures were present in one third and just under half had gastro-oesophageal reflux. Dysphagia was present in about $65 \%$ in all age groups but symptom severity and surgical intervention decreased significantly after 5 years of age. Gastro-oesophageal reflux symptoms were commoner in the older patients increasing from $18 \%$ in the group under 5 years of age to $52 \%$ in those over 15 years. Height centile distribution was normal, but the median weight centile was the 25th. Weight for height values greater than 2 SD below the mean were present in 13\%, and two thirds of these patients were under 5 years of age. The majority of adults enjoyed a normal lifestyle and were comparable with their peers.
\end{abstract}

(Arch Dis Child 1993;68:163-6)

Successful surgical management of oesophageal atresia by alimentary continuity was first reported in the early 1940 s. $^{1}$ Since then there has been a rapid decline in the perioperative mortality ${ }^{2-6}$ and this is now usually related to the presence of associated congenital abnormalities. ${ }^{7}$ Morbidity from oesophageal complications in survivors is well documented and is secondary to anastomotic strictures, ${ }^{3} 589$ disordered motility ${ }^{10-13}$ and gastro-oesophageal reflux. ${ }^{14-17}$ The impact of these problems on the nutritional status of the patients ${ }^{18-21}$ and parental feeding practices ${ }^{21} 22$ has been studied in small and selected groups.

Knowledge of the prevalence and severity of upper gastrointestinal problems and anthropometric data in a large number of unselected patients of all ages after surgical repair of oesophageal atresia and tracheo-oesophageal fistula would be invaluable to paediatricians and paediatric surgeons, and would be helpful in assessing the level of medical and paramedical input required by the patients' families. This study reports the oesophageal morbidity and nutritional status of over 300 children and adults-over $90 \%$ of all the survivors born with oesophageal atresia from a major centre. Respiratory problems and lung function data in these patients will be reported elsewhere.

\section{Patients and methods}

Five hundred and thirty eight patients with oesophageal atresia and tracheo-oesophageal fistula were managed at the Royal Children's Hospital, Melbourne, from the first successful repair in 1948 until 1986. Three hundred and sixty six patients survived of whom 302 were interviewed and examined as part of a follow up study, and information was available from a telephone interview for a further 32 patients. The majority of adult patients were accompanied by their parents.

The following information was recorded from the case notes: type of oesophageal atresia, details of subsequent hospital admissions for oesophageal complications including surgical procedures, and radiological and endoscopic evidence of gastro-oesophageal reflux. Patients were defined as having anastomotic stricture if two or more oesophageal dilatations were performed. The types and management of other congenital anomalies were also recorded.

Details of medical history and health problems in the previous 12 months with emphasis on gastrointestinal symptoms were obtained from the patient and where possible the parents. The frequency of dysphagia, oesophageal food impaction, prolonged meal times, and gastrooesophageal reflux symptoms were recorded. The latter was defined as effortless vomiting after feeds in the younger patients and regurgitation of food and heartburn in the older group.

Each patient was examined and height $(\mathrm{cm})$ and weight $(\mathrm{kg})$ measurements recorded. All values were expressed to the nearest centile based on standardised data. ${ }^{23}$ Values above and below 2 SD from the mean were recorded separately. Weight for height SD scores were calculated.

The $\chi^{2}$ test was used to analyse the relationship between current feeding difficulties and gastrooesophageal reflux symptoms.

\section{Results}

Data on 334 patients aged 1-37 years are

Table 1 Age and sex distribution

\begin{tabular}{|c|c|c|c|c|}
\hline & \multicolumn{4}{|c|}{ Age (years) } \\
\hline & $\overline{0-5}$ & $5-10$ & $10-15$ & $>15$ \\
\hline $\begin{array}{l}\text { Male } \\
\text { Female }\end{array}$ & $\begin{array}{l}39 \\
23\end{array}$ & $\begin{array}{l}30 \\
24\end{array}$ & $\begin{array}{l}31 \\
23\end{array}$ & $\begin{array}{l}92 \\
72\end{array}$ \\
\hline
\end{tabular}

Department of Paediatrics, The General Infirmary at Leeds,

Clarendon Wing,

Leeds LS2 9NS.

Accepted 30 September 1992 
presented. The age and sex distribution is shown in table 1. Two hundred and ninety patients $(87 \%)$ had oesophageal atresia and distal tracheo-oesophageal fistula. Atresia and proximal fistula was present in six (2\%), atresia alone in $16(5 \%)$, and a fistula with intact oesophagus in $22(6 \%)$. Other congenital abnormalities were present in $187(56 \%)$ and are shown in table 2.

Two hundred and twenty one patients $(67 \%)$

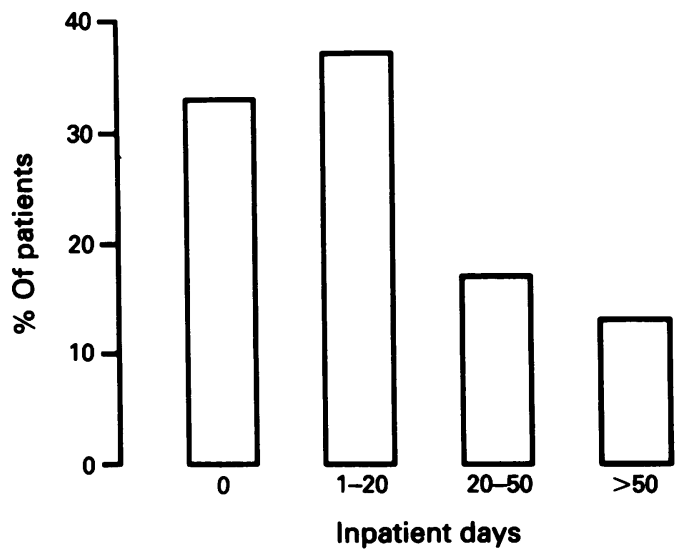

Figure 1 Total inpatient days for problems related to the oesophagus.

Table 3 Frequency of subsequent surgical procedures

\begin{tabular}{lr}
\hline & No (\%) \\
\hline Oesophageal dilatation $(\geqslant 1)$ & $158(47)$ \\
Foreign body removal $(\geqslant 1)$ & $97(29)$ \\
Oesophageal stricture resection & $35(11)$ \\
Fundoplication & $42(13)$ \\
Division of recurrent fistula & $20(6)$ \\
\hline
\end{tabular}

Table 4 Frequency of oesophageal dilatations

\begin{tabular}{lr}
\hline No of dilatations & No $(\%)$ \\
\hline 0 & $178(53)$ \\
1 & $38(12)$ \\
$2-5$ & $70(21)$ \\
$6-10$ & $28(8)$ \\
$11-20$ & $13(4)$ \\
$>20$ & $7(2)$ \\
\hline
\end{tabular}

Table 2 Frequency of associated congenital abnormalities $(n=187)$

\begin{tabular}{lr}
\hline Abnormality & $\%$ \\
\hline Vertebral & 17 \\
Anorectal & 10 \\
Cardiac & 12 \\
Renal & 25 \\
Radial & 1 \\
Limb & 7 \\
Digital & 4 \\
Chromosomal & 2 \\
Syndromes & 3 \\
Other & 19 \\
\hline
\end{tabular}

Figure 2 Prevalence of feeding difficulties in childhood

(shaded area indicates surgical intervention) for all ages.

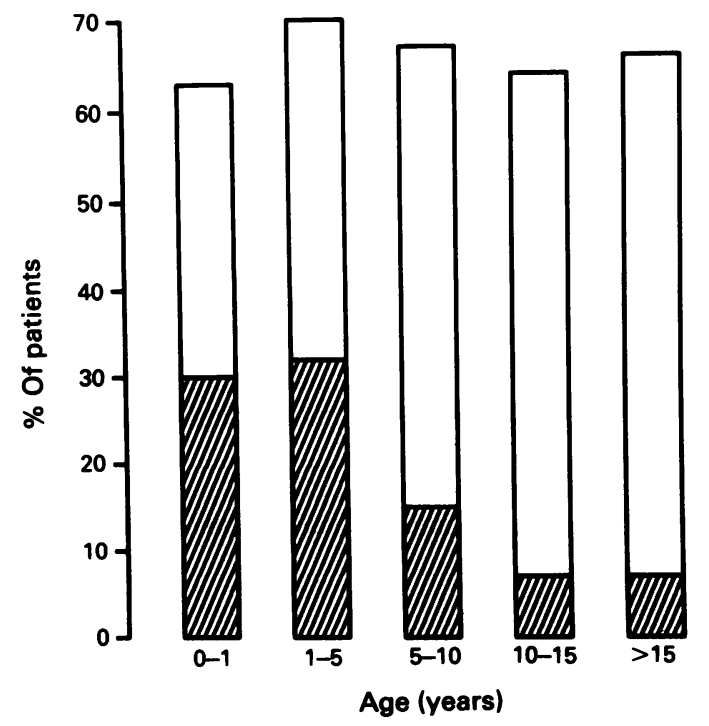

were hospitalised with oesophageal complications in the years after initial surgery, and the number of inpatient days is shown in fig 1 . The surgical procedures undertaken and the frequency of oesophageal dilatations are shown in tables 3 and 4, respectively. Anastomotic strictures were present in $118(35 \%)$ and gastrooesophageal reflux was diagnosed in $142(43 \%)$ in the five years after initial surgery. Sixteen patients had oesophageal replacement surgery and in 11 this was the primary procedure for achieving alimentary continuity. One hundred and seventy five patients ( $52 \%$ ) had surgery as a result of other congenital abnormalities.

The prevalence of feeding difficulties (dysphagia, food impaction, prolonged mealtimes) in different age groups for all ages and

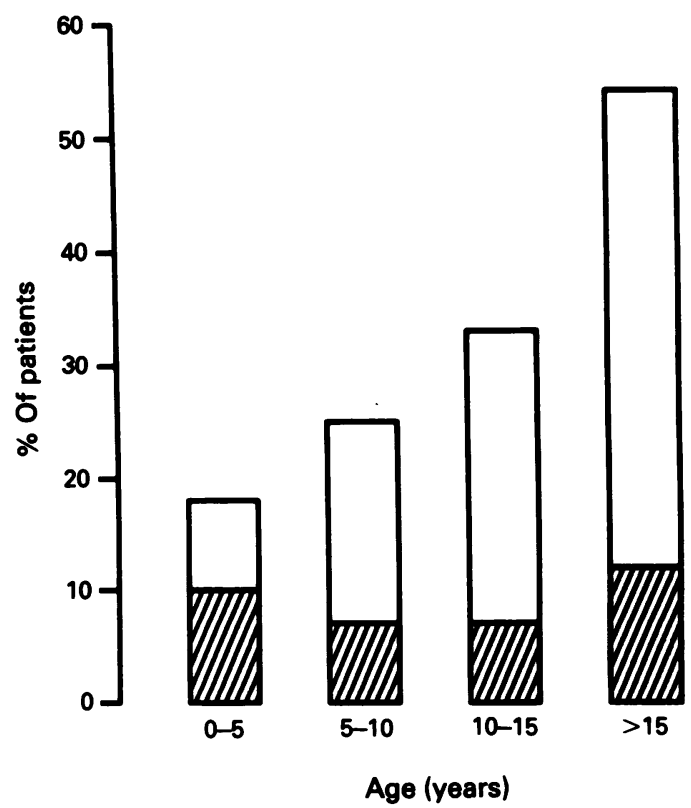

Figure 3 Prevalence of feeding difficulties in the 12 months before review (shaded area indicates daily symptoms).

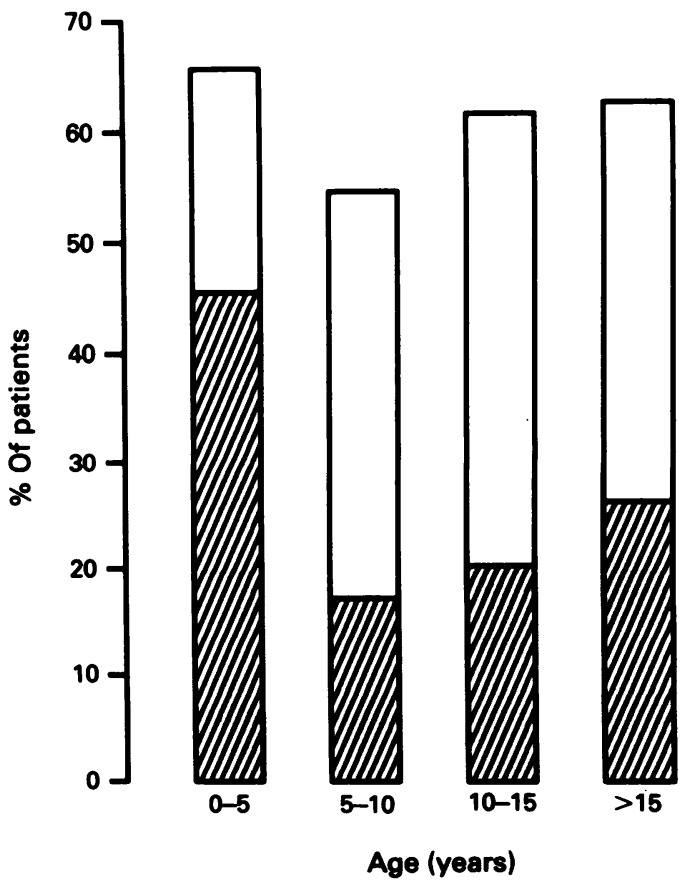

Figure 4 Prevalence of gastro-oesophageal reflux symptoms in the 12 months before review (shaded area indicates daily symptoms). 
the age distribution of surgical interventions are shown in fig 2. Upper gastrointestinal symptoms in the 12 months before review for different ages are shown in figs 3 and 4 . There was no significant relationship between current gastrooesophageal reflux symptoms and current feeding difficulties $(p>0.5)$. While many older patients experienced symptoms, in the majority
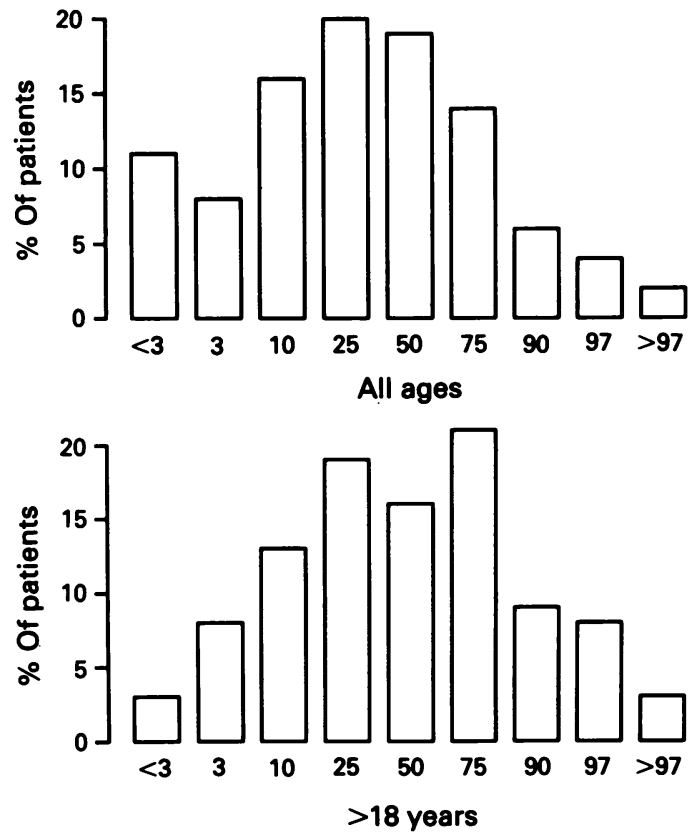

Figure 5 Percentage distribution of all patients and adult patients weight expressed to nearest centile.
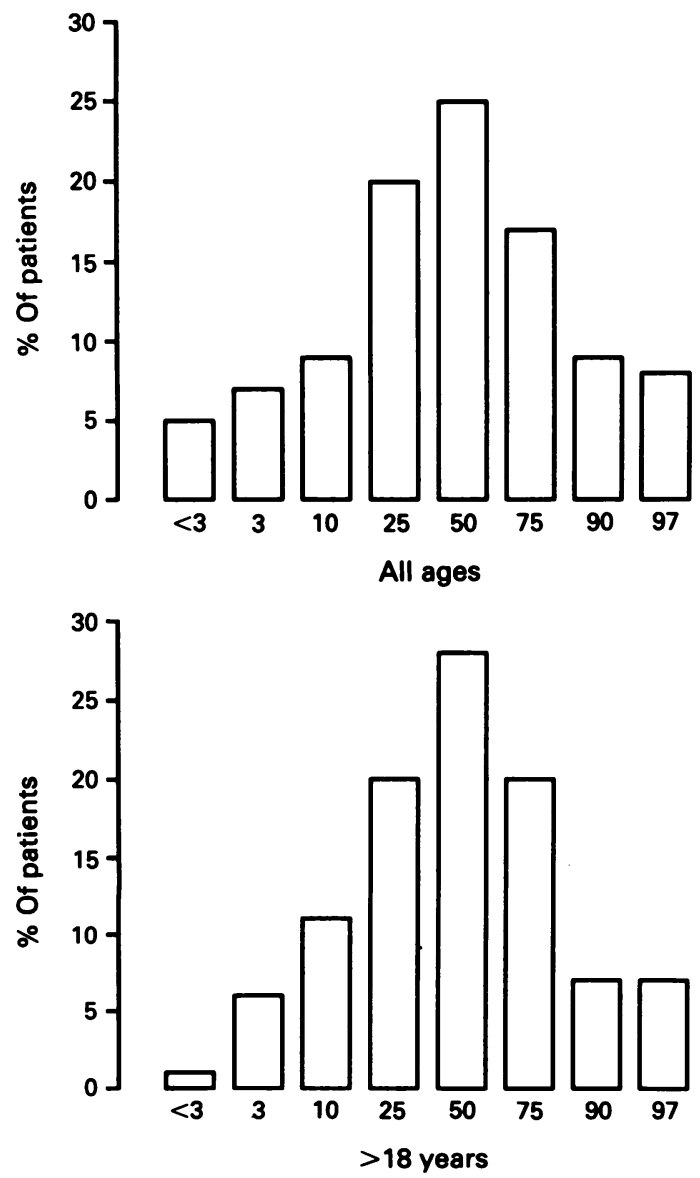

Figure 6 Percentage distribution of all patients and adult patients height expressed to nearest centile. these were not considered as being major. Poultry, meats, and bread were considered particularly difficult to swallow and many drank fluids with their meals. Eleven patients attended special schools and seven had invalid pensions none as a direct result of oesophageal complications.

Height and weight centiles for all patients and adult patients are shown in figs 5 and 6 . Weight for height greater than $2 \mathrm{SD}$ below the mean was present in $38(13 \%)$ : 20 were under 5 years of age, 10 were 5-10 years, seven were 10-15 years, and one over 15 years. These patients were more likely to have had more severe oesophageal complications.

\section{Discussion}

This study on a large number of patients after surgical repair of oesophageal atresia and tracheo-oesophageal fistula shows that oesophageal complications are common. Two thirds were rehospitalised and half underwent one or more further surgical procedures. Thirteen percent were admitted for more than 50 days. While dysphagia was present in two thirds of all age groups, the frequency and severity of symptoms and surgical intervention declined sharply after 5 years. Significant nutritional compromise was present in $13 \%$ and these were mainly younger patients. The majority of older patients did not feel that their upper gastrointestinal symptoms were major, enjoyed a normal lifestyle, and their growth parameters were comparable with their peers.

The results of our study will enable paediatricians and paediatric surgeons to be very encouraging to parents about the long term outcome of oesophageal atresia and/or tracheooesophageal fistula. The early postoperative years, however, may be difficult with major feeding difficulties and multiple hospital admissions. The psychological and social impact of these problems on the child and his family may be enormous. ${ }^{24} \mathrm{~A}$ recent study has suggested that parents are not adequately prepared for these problems. ${ }^{21}$ On the basis of our findings we would advocate that optimal advice and support is offered to parents as soon as possible after initial surgery.

In contrast to other studies ${ }^{18-21}$ stunting of growth (height for age less than 2 SD below the mean) in our patients was uncommon, but the prevalence of wasting (weight for height less than 2 SD below the mean) was similar. Those studies were based on small numbers and in one anthropometric data was collected from parents by questionnaire. ${ }^{21}$ This group may well have had more severe problems as they were members of an oesophageal atresia parent support group. In our population wasting was commoner in children under 5 years, and weight centile distribution for adult patients was normal. In one study of 43 patients with serial weight measurements over 12 years, the acute malnutrition present in the early years resolved completely, ${ }^{19}$ supporting our view that the long term nutritional outcome is excellent.

Dysphagia was common in all age groups but less severe in older patients and is secondary to 
anastomotic stricture and disordered oesophageal motility. Stricture is uncommon after 5 years of age presumably as a result of oesophageal growth and many factors may contribute to its formation: rough handling of the oesophagus at the time of repair, tension on the anastomosis, the use of silk sutures, ${ }^{9}$ gastro-oesophageal reflux, anastamotic dehiscence, and two layered anastomoses. ${ }^{25}$ Motor dysfunction of the oesophagus is likely to be universal in these patients. Abnormal innervation of the oesophagus and stomach seen on postmortem specimens, ${ }^{26}$ motor incoordination of the proximal and distal oesophageal body in preoperative studies ${ }^{27}$ and in patients with $\mathbf{H}$ type tracheo-oesophageal fistulas, ${ }^{28} 29$ and the finding of abnormal oesophageal motility in puppies ${ }^{30} 31$ after oesophageal mobilisation, transection, and resuture would suggest a congenital aetiology.

Gastro-oesophageal reflux was documented in nearly half the group in the first 5 years after initial surgery, similar to the findings of published studies on small numbers, ${ }^{14-17}$ but symptomatic evidence was present in only $18 \%$ under 5, suggesting that it is likely to be present at a subclinical level. Inherent oesophageal denervation, ${ }^{26}$ vagal nerve damage, traction to the lower oesophagus, and gastrostomy ${ }^{9}$ may all contribute to this. Symptomatic gastrooesophageal reflux was much commoner in older patients and may in part be due to an increased willingness of older patients to admit to symptoms. Despite this in the majority these symptoms were mild and infrequent, and up to one third of adults in the general population may have occasional gastro-oesophageal reflux symptoms. $^{32}$

The long term outcome of babies born with oesophageal atresia and/or tracheo-oesophageal fistula, despite a potentially difficult initial period as a result of oesophageal complications, respiratory morbidity, and associated congenital anomalies, is excellent. It is unlikely that surgical advances in the next decade will have a major impact on the prevalence of oesophageal complications in young children, but potentially treatable risk factors such as gastro-oesophageal reflux should be identified early. Maximum support should be offered to parents and children to minimise the traumatic effects of frequent surgical intervention and hospitalisation in these patients.

1 Haight C, Towsley $\mathrm{H}$. Congenital atresia of the esophagus with tracheo-esophageal fistula. Extrapleural ligation of fistula and end-to-end anastomosis of esophageal segments. Surg Gynecol Obstet 1943;76:672-88.

2 Myers NA. Oesophageal atresia and/or tracheo-esophageal fistula. A study in mortality. Prog Pediatr Surg 1979;13: 141-65.

3 Louhimo I, Lindahl H. Esophageal atresia: primary results of 500 consecutively treated patients. $\mathcal{F}$ Pediatr Surg 1983;18:217-29.

4 Bishop P, Klein M, Philippart A, Hixson D, Hertzler J. Transpleural repair of esophageal atresia without a primary gastrostomy: 240 patients treated between 1951 and 1983. f Pediatr Surg 1985;20:823-8.

5 Manning P, Morgan R, Coran A, et al. Fifty years experience with esophageal atresia and tracheoesophageal fistula. Ann Surg 1986;204:446-51.

6 Silten V, Hagberg S, Rubenson A, Werkmaster K. Management of esophageal atresia: review of 16 years experience. F Pediatr Surg 1988;23:805-9.

7 Ein S, Shandling B, Wesson D, Filler R. Esophageal atresia with distal tracheoesophageal fistula: associated anomalies and prognosis in the 1980's. F Pediatr Surg 1989;24:1055-9.

8 Hicks L, Mansfield P. Esophageal atresia and tracheoesophageal fistula. Review of thirteen years' experience. $\mathcal{F}$ Thorac Cardiovasc Surg 1981;81:358-63.

9 Spitz L, Kiely E, Brereton R. Esophageal atresia: five year experience with 148 cases. 7 Pediatr Surg 1987;22:103-8.

10 Desjardins J, Stephens C, Moes C. Results of surgical treatment of congenital tracheo-esophageal fistula with a note on cinefluorographic findings. Ann Surg 1964;160:141-5.

11 Shepard R, Fenn S, Sieber W. Evaluation of esophageal function in post-operative esophageal atresia and tracheoesophageal fistula. Surgery 1967;59:608-18.

12 Burgess J, Carlson H, Ellis F. Esophageal function after successful repair of esophageal atresia and tracheoesophageal fistula-a manometric and cine-fluorographic study. F Thorac Cardiovasc Surg 1968;56:667-73.

13 Laks H, Wilkinson R, Schuster S. Long term results following correction of esophageal atresia with tracheo-esophageal
fistula. A clinical and cine-fluorographic study. $\mathcal{F}$ Pediatr Surg 1972;7:591-7.

14 Orringer $M$, Kirsh $M$, Sloan $H$. Long-term esophageal function following repair of esophageal atresia. Ann Surg 1977; 186:436-43.

15 Jolley S, Johnson D, Roberts C, Herbst L. Patterns of gastroesophageal reflux in children following repair of esophageal atresia and distral tracheo-esophageal fistula. $\mathcal{F}$ Pediatr Surg 1980;15:857-62.

16 Leendertse-Verloop K, Tibboel D, Hazebroek F, Molenaar J. Post-operative morbidity in patients with oesophageal atresia. Pediatric Surgery Intermational 1987;2:2-5.

$17^{\circ}$ McKinnon L, Kosloske A. Prediction and prevention of anastomotic complications of esophageal atresia and tracheoesophageal fistula. F Pediatr Surg 1990;25:778-81.

18 Andrassy R, Patternson R, Ashley J, Patrissi G, Mahour G. Long-term nutritional assessment of patients with esophageal atresia and/or tracheoesophageal fistula. f Pediatr Surg 1983;18:431-5.

19 Lindahl H. Long-term prognosis of successfully operated esophageal atresia with aspects on physical and psychological development. $Z$ Kinderchir 1984;39:6-10.

20 Gutierrez-Sanroman C, Vila-Carbo J, Segarra-Llido V, Garcia-Sala C, Ruiz-Company S. Long-term nutritional evaluation of 70 patients operated on for esophageal atresia. Pediatric Surgery International 1988;3:123-7.

21 Puntis J W L, Ritson D G, Holden C E, Buick R G. Growth and feeding problems after repair of oesophageal atresia. Arch Dis Child 1990;65:84-8.

22 Smith I, Beck J. Mechanical feeding difficulties after primary repair of oesophageal atresia. Acta Paediatr Scand 1985;74: $237-8$.

23 Tanner JM, Whitehouse RH, Takaishi M. Standards from birth to maturity for height, weight, height velocity and weight velocity: British children, 1965. Arch Dis Child 1966;41:613-35.

24 Koop C, Schnaufer L, Thompson G, Haecker T, Dalrymple $D$. The social, psychological and economic problems of the patients' family after successful repair of esophageal atresia. Z Kinderschir 1975;17:125-31.

25 Coran A. Current management of oesophageal atresia and tracheo-oesophageal fistula. Bull Soc Sci Med Grand Duche Luxemb 1989;3:29-51.

26 Nakazato Y, Landing B, Wells T. Abnormal auerbach plexus in the esophagus and stomach of patients with esophageal atresia and tracheo-esophageal fistula. $f$ Pediatr Surg 1986; 21:831-7.

27 Romeo G, Zuccarello B, Proietto F, Romeo C. Disorders of the esophageal motor activity in atresia of the esophagus. f Pediatr Surg 1987;22:120-4.

28 Kirkpatrick J, Cresson S, Pilling G. The motor activity of the esophagus in association with esophageal atresia and tracheo-esophageal fistula. American foumal of Roentgenotracheo-esophageal fistula. American foum
logy and Radium Therapy 1961;86:884-7.

29 Johnston P, Hastings N. Congenital tracheo-esophageal fistula without esophageal atresia. A m f Surg 1966;112:233.

30 Carveth S, Schlegel J, Code F, Ellis F. Esophageal motility after vagotomy, phenicotomy, myotomy and myomectomy in dogs. Surg Gymecol Obstet 1962;114:31-42.

31 Haller J, Broker A, Talbert J. Esophageal function following resection. Studies in newborn puppies. Ann Thorac Surg 1966;2:180-7.

32 Nebel O, Fornes M, Castell D. Symptomatic gastrooesophageal reflux: incience and precipitating factors. Dig Dis 1976;21:953-6. 